\title{
FACTORS AFFECTING PARENTAL RESISTANCE TO THE USE OF SMARTPHONES FOR LEARNING PURPOSES AT SCHOOLS
}

\author{
Shlomit Hadad ${ }^{1}$, Hagit Meishar-Tal ${ }^{2}$ and Ina Blau ${ }^{1}$ \\ ${ }^{I}$ The Open University of Israel \\ ${ }^{2}$ HIT - Holon Institute of Technology, The Open University of Israel
}

\begin{abstract}
This study examined parental resistance to the use of smartphones in schools, the resistance factors underlying the parental resistance and other factors that predict this resistance. The data was collected from 220 parents who filled in an online questionnaire. The participants reported on their level of resistance to the use of smartphones in schools (no resistance, passive resistance, active resistance) and the resistance factors (pedagogic, social, environmental and economic factors) underlying this resistance. About two-thirds of the parents who participated in the study resisted to the use of smartphones in school, and more than half of them expressed active resistance to such use. The social resistance factor found to be the highest in the study, while the pedagogical resistance factor was the lowest. Nevertheless, both these factors, and the economic factor, were positive predictors of parental resistance level. The research sheds light on the phenomenon of parents' resistance to the use of smartphones in school learning, discuss the implication of this phenomenon on school policy and suggest practical solution for schools to overcome the parental resistance.
\end{abstract}

\section{KEYWORDS}

Smartphones, Parents, Resistance to Technology

\section{INTRODUCTION}

In recent years, with the rise in the number of smartphones owned by students, there is an ongoing debate between parents, educators and policymakers regarding the integration of smartphones into school learning processes. Smartphones offer a variety of learning applications and facilitate collaborative and accessible learning (Barrs, 2011; Meishar-Tal \& Gross, 2014). However, despite this potential for empowering learning, many parents in Israel have expressed negative attitude towards the use of smartphones in schools. Parents have even appealed to the High Court of Justice to prevent their use in education, which eventually led to a ban on the use of these devices in schools (The Israeli Ministry of Education, 2016).

A variety of theoretical frameworks explains adoption and rejection of technologies. Among the well-known approaches are Technology Acceptance Model (Davis, 1989) and The Unified Theory of Acceptance and Use of Technology (Venkatesh et al., 2003). These theories explain rejection to technology as lack of acceptance, mainly in terms of "ease of use" and "usefulness". One the other hand, "Three Pillars of Technological Rejection" model, (Murthy and Mani, 2013) refers to resistance to technology as an independent phenomenon stemming from social, economic and environmental factors.

Moreover, resistance to the use technology in schools has been discussed extensively in the literature in regard to teachers' pedagogical attitudes (Hall \& Hord, 1987) and even students' (Sung, Chang \& Liu, 2016), but much less attention has been payed to the parental resistance. The parents' resistance to using Smartphones in schools could be understood in light of the fact that Internet use by children is usually associated with social dangers and risks such as bullying, racism and sexual harassment (Livingstone \& Haddon, 2009). Use of smartphones by children is also associated with addiction and social loneliness (Bian \& Leung, 2015; Genc, 2014). Parents are also concerned about the environmental risks (exposure to radiation) and high economic cost of using Smartphones by their children (Genc, 2014). Identifying the parental resistance factors, and which factors predict the parental actual resistance - may contribute to the understanding of this phenomenon and can serve policymakers in defining ways to overcome this resistance. 


\section{METHOD}

\subsection{Participants}

The participants included 220 Israeli parents, most of them mothers $(89 \%)$. About half of the parents had a child studying in a middle school, and the rest had children in elementary and high schools. The majority of the participants' children $(60 \%)$ studied in state-secular education, while $28 \%$ studied state-religious education, and the rest - in the ultra-orthodox schools. About $45 \%$ from the parents were non-religious, $28 \%$ traditional and the rest of them religious people. The level of income was also examined, $37 \%$ were average income, $28 \%$ below and $35 \%$ above the average income. Finally, $77 \%$ of the children have a smartphone.

\subsection{Instruments and Procedure}

The research was conducted within the quantitative paradigm through online questionnaires distributed among groups of parents via social networks. The questionnaire included the following measurements:

The actual parental resistance was examined as non-resistance, passive and active resistance, based on studies of resistance to change in general and about parental involvement (Fisher \& Friedman, 2009; Oreg, 2006).

The resistance factors were measured by four resistance factors, three of the factors: social, environmental, economic - were based on the Three Pillars of Technological Rejection model (Murthy $\&$ Mani, 2013) and the pedagogical factor was based on the Concerns Based Adoption model (Hall \& Hord, 1987). All the scales demonstrated good reliability: social $(\alpha=.87)$, economic $(\alpha=.83)$, environmental $(\alpha=.88)$ and pedagogical $(\alpha=.84)$.

The research questions were:

RQ1: What is the level of resistance to smartphone use among parents?

RQ2: What are the dominant resistance factors for using Smartphone in schools? (social, environmental, economic, and pedagogical)

RQ3: Are there differences between the resistance factors in each parental resistance group?

RQ4: Which of the factors predict the actual level of parental resistance?

\section{RESULTS}

\subsection{The Actual Parental Resistance to the use of Smartphones in Learning}

The resistance level to the use of smartphones at schools measured three parental resistance levels: non-resistance, passive and active resistance. The active resistance was rated as several resistance levels as shown in Figure 1. 


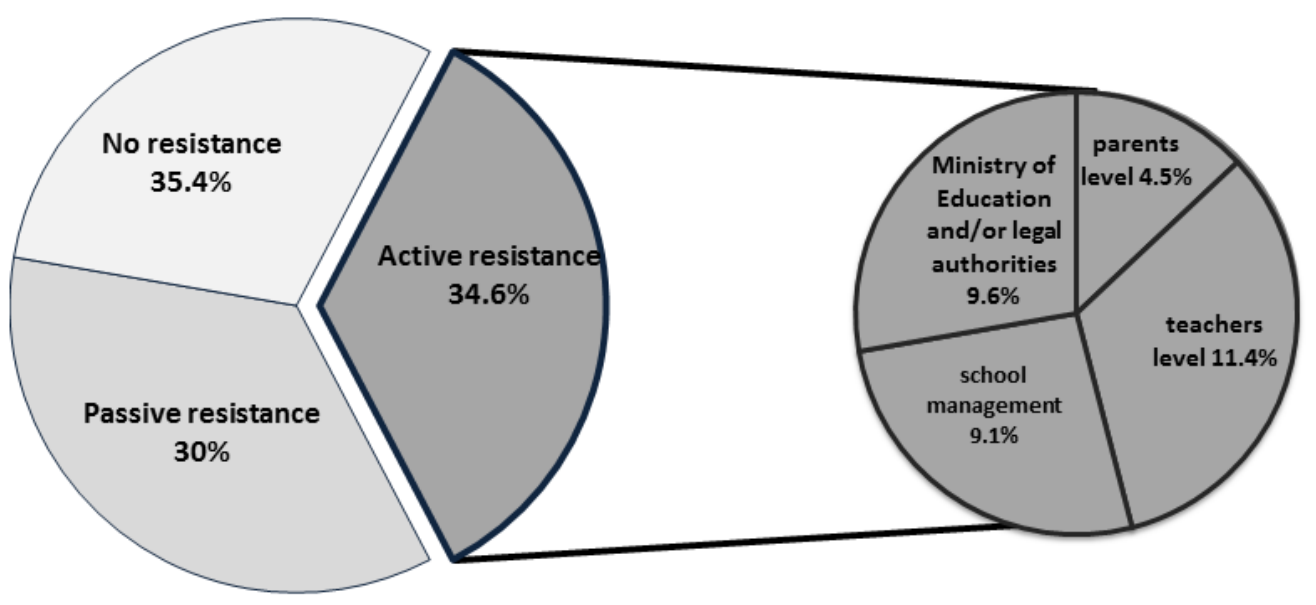

Figure 1. Distribution of parents' resistance to educational use of smartphones $(n=220)$

As can be seen, $64.6 \%$ of parents resisted their children's use of a smartphone, $30 \%$ of them expressed passive resisted, while $34.6 \%$ expressed active resistance to the use.

\subsection{The Dominant Resistance Factor to the use of Smartphones in Learning}

In order to examine which factors between the four factors (social, environmental, economic and pedagogical) are most dominant and whether there are differences between these factors, analysis of variance with repeated measurements was conducted and a significant difference was found between the four groups $\mathrm{F}(3,216)=73.80, p=.000,{ }_{\mathrm{p}} \eta^{2}=.232$. Table 1 presents descriptive statistics.

Table 1. Descriptive statistics for the resistance factors questionnaire $(\mathrm{n}=220)$

\begin{tabular}{lcccc}
\hline Variable & Mean $(\mathrm{sd})$ & Median & $\begin{array}{c}\text { Skewness } \\
(\mathrm{sd})\end{array}$ & Range \\
\hline Social resistance & $3.57(1.11)$ & 3.75 & $-.489(.164)$ & $1.00-5.00$ \\
Economic resistance & $3.45(1.13)$ & 3.50 & $-.257(.164)$ & $1.00-5.00$ \\
Environmental resistance & $3.23(1.16)$ & 3.25 & $-.168(.164)$ & $1.00-5.00$ \\
Pedagogical resistance & $2.83(1.12)$ & 2.80 & $.159(.164)$ & $1.00-5.00$ \\
\hline
\end{tabular}

Pairwise comparisons showed that the average of the pedagogical resistance factors $(M=2.83)$ was significantly lower than the social resistance $(M=3.57)$, environmental resistance $(M=3.23)$ and economic resistance factors $\left(\mathrm{M}=3.45, p^{\prime} \mathrm{s}=.000\right)$. The social resistance was significantly higher than pedagogical and environmental factors, but no significant differences were found between them and the economic factors $(\mathrm{p}=.056)$. In addition, the environmental factors were significantly lower than the social rejection factors $(\mathrm{p}=.001)$.

\subsection{The Differences between the Resistance Factors in each Resistance Group's Level}

In order to examine the differences between the resistance factors among the parents in each resistance group, particularly to reveal the dominant factors in the active parental resistance, repeated measures ANOVA tests were conducted separately for each resistance level. Table 2 presents the results. 
Table 2. Differences in resistance factors at different levels of actual parental resistance $(n=220)$

\begin{tabular}{ccccccc}
\hline & $\begin{array}{c}\text { Pedagogical } \\
\text { resistance } \\
\mathrm{A}\end{array}$ & $\begin{array}{c}\text { Society } \\
\text { resistance } \\
\mathrm{B}\end{array}$ & $\begin{array}{c}\text { Environmental } \\
\text { resistance } \\
\mathrm{C}\end{array}$ & $\begin{array}{c}\text { Economical } \\
\text { resistance } \\
\mathrm{D}\end{array}$ & $\mathrm{F}$ & $\begin{array}{c}\text { Pairwise } \\
\text { comparisons: } \\
\text { Bonferroni } \\
\text { correction }\end{array}$ \\
\hline $\begin{array}{c}\text { Actual parental } \\
\text { resistance }\end{array}$ & $M$ & $M$ & $M$ & $M$ & & \\
\hline $\begin{array}{c}\text { Non-resistance } \\
(n=78)\end{array}$ & 1.86 & 2.64 & 2.25 & 2.78 & $F(3,231)=41.81$, & $\mathrm{C}<\mathrm{B} \& \mathrm{D}$, \\
\hline $\begin{array}{c}\text { Passive-resistance } \\
(n=66)\end{array}$ & $(0.72)$ & $(0.97)$ & $(0.52)$ & $(0.97)$ & $\boldsymbol{p}=\mathbf{. 0 0 0}, \mathrm{p} \eta^{2}=.352$ & $\mathrm{~A}<\mathrm{B}, \mathrm{C}, \mathrm{D}$ \\
\hline $\begin{array}{c}\text { Active-resistance } \\
(n=76)\end{array}$ & 3.08 & 3.89 & 3.52 & 3.46 & $F(3,195)=18.09$, & $\mathrm{B}>\mathrm{C} \& \mathrm{D}$, \\
$\mathrm{A})$ & $(0.88)$ & $(0.80)$ & $(0.91)$ & $(1.07)$ & $\boldsymbol{p}=. \mathbf{0 0 0}, \mathrm{p} \eta^{2}=.218$ & $\mathrm{~A}<\mathrm{B}, \mathrm{C}, \mathrm{D}$ \\
\hline
\end{tabular}

The pedagogical resistance factors were found to be the lowest at all parental resistance levels. In addition, for parents who reported non-resistance, the environmental resistance was low compared to social and economic factors. On the other hand, for passive and active resistance groups, social resistance overcame environmental resistance.

\subsection{The Resistance Factors Predicting the Parents' Actual Level of Resistance}

In order to examine the factors predicting the parents' actual level of resistance, two-steps regression analysis was performed. The first step included the demographic and socioeconomic variables, and explained $5.2 \%$ of the variance in the level of actual parental resistance. In the second step, the resistance factors explained additional $39.1 \%$ of the variance. Altogether these factors explained $44.3 \%$ of parental resistance level variance, $F(10,209)=16.597, p=.000$. Table 3 shows the regression result.

Table 3 Regression of resistance factors as predictors of parental resistance level

\begin{tabular}{lccl}
\hline Variable & $\beta$ & \multicolumn{1}{l}{} & \\
\hline Step 1 & & & \\
Parent gender & .010 & .153 & .879 \\
Have smartphone (child) & -.106 & -1.446 & .150 \\
Education stage & -.018 & -.248 & .805 \\
Religiosity level & .134 & 1.929 & $\mathbf{. 0 5 5}$ \\
Education degree (parent) & -.064 & -.878 & .381 \\
Income level & -.078 & -1.072 & .285 \\
\hline Step 2 & & & \\
Parent gender & -.029 & -.555 & .580 \\
Have smartphone (child) & -.025 & -.430 & .668 \\
Education stage & -.006 & -.106 & .916 \\
Religiosity level & .005 & .096 & .923 \\
Education degree (parent) & -.005 & -.085 & .932 \\
Income level & -.028 & -.488 & .626 \\
Pedagogical resistance & .321 & 2.910 & $\mathbf{. 0 0 4}$ \\
Society resistance & .240 & 2.283 & $\mathbf{. 0 2 3}$ \\
Economy resistance & .183 & 1.545 & .124 \\
Environmental resistance & -.070 & -.935 & .351 \\
\hline
\end{tabular}

As can been seen, in step 1, positive predictability was found for the religiosity level (borderline significance), so the higher the level of religiosity of a parent, the more he/she resists to using smartphones in schools. In step 2, among the four resistance factor, positive predictability was found only for the pedagogical and the social resistance factors, while religiosity was not any more a significant predictor of actual parental resistance. 


\section{CONCLUSION}

This study examined parental resistance to the use of smartphones in schools, the resistance factors underlying the parental resistance and the factors predicted the parental resistance level. About $65 \%$ of the parents who participated in this study resisted to the use of smartphones in school, and more than half of them expressed active resistance. The high rate of parents who résistance the use of smartphones in learning regardless of their personal differences indicates that the resistance to smartphone use among parents is a widespread phenomenon and requires examination of the factors affecting this resistance.

The findings indicated that social and economical factors were the highest among resistance factors while the pedagogical factor was the lowest. It could be explained in light of Bian \& Leung (2015) study that reflected the parents' fear of exposure to inappropriate and harmful content on the Internet. The low level of pedagogical resistance may indicate that parents did not perceive the smartphone as a major resource of learning, they unaware of the pedagogic aspects of learning with smartphones. On the other hand, pedagogical and social factor significantly predicted high parental resistance level, indicate that parents, whose resistance was pedagogically or socially motivated, are those who will actually take their objections to the Ministry of Education and to court.

These findings indicate that active resistance and parental intervention in educational policy does not require a majority of active parents, even a minority can be enough to change the existing educational policy as long as there is an atmosphere of resistance among parents. We recommend that policymakers in the Israeli education system will act to increase awareness of the importance of integrating smartphones into learning among parents, while taking into account the pedagogic and social factors underlying the active resistance of parents.

\section{REFERENCES}

Barrs, K. (2011). Mobility in learning: The feasibility of encouraging language learning on smartphones. Studies in Self-Access Learning Journal, 2(3), 228-233.

Bian, M., \& Leung, L. (2015). Linking loneliness, shyness, smartphone addiction symptoms, and patterns of smartphone use to social capital. Social Science Computer Review, 33(1), 61-79.

Davis, F. D. (1989). Perceived usefulness, perceived ease of use, and user information Technology. MIS Quarterly, 13, 3, 319-339.

Fisher. Y., Friedman. Y. (2009). Parents and School: Interaction and Involvement. Pages Journal, 47, 11-40.

Genc, Z. (2014). Parents' perceptions about the mobile technology use of preschool aged children. Procedia-Social and Behavioral Sciences, 146, 55-60.

Hall, G. E., Hord, S. M. (1987). Change in schools: Facilitating the process. Albany: State University of New York Press.

Livingstone, S., and Haddon, L. (2009) Introduction. In S. Livingstone and L. Haddon (Eds.), Kids Online: Opportunities and Risks for Children (1-15). Bristol: The Policy Press

Meishar-Tal, H. \& Gross, M., 2014. Teaching Sustainability via Smartphone-Enhanced Experiential Learning in a Botanical Garden. International Journal of Interactive Mobile Technologies (iJIM), Vol.8, No. 1, pp-10.

Murthy, S. R., Mani, M. (2013). Discerning Rejection of Technology. Sage Open, 3 (2). doi: $10.1177 / 2158244013485248$

Oreg, S. (2006). Personality, context, and resistance to organizational change. European Journal of Work and Organizational Psychology, 15(1), 73-101.

Sung, Y. Chang, K., \& Liu, T. (2016). The Effects of integrating mobile devices with teaching and learning on students' learning performance: A Meta-analysis and research synthesis. Computers \& Education, 94, 252-275.

The Israeli Ministry of Education (2016). Students use endpoints for learning purposes. Information and Computer Technology Division.

Venkatesh, V., Morris, M. G., Davis, G. B., \& Davis, F. D. (2003). User acceptance of information technology: Toward a unified view. MIS Quarterly, 27(3), 425-478. 